\section{Relationship of Instrumental and Sensory Texture Measurements of Fresh and Stored Apples to Cell Number and Size}

\author{
Harpartap Mann, David Bedford, and James Luby \\ Department of Horticultural Science, University of Minnesota, 1970 Folwell \\ Avenue, St. Paul, MN 55108
}

\author{
Zata Vickers \\ Department of Food Science and Nutrition, University of Minnesota, 1334 \\ Eckles Avenue, St. Paul, MN 55108
}

\section{Cindy Tong}

Department of Horticultural Science, University of Minnesota, 1970 Folwell Avenue, St. Paul, MN 55108

\begin{abstract}
Additional index words. confocal laser scanning microscopy, Crispness, Firmness, Malus $\times$ domestica, sensory evaluations, texture
\end{abstract}

\begin{abstract}
During storage, many apple (Malus $\times$ domestica Borkh.) genotypes lose their desirable textural qualities, but some like 'Honeycrisp', maintain their sensory Crispness and Firmness. To understand this differential response of genotypes to postharvest changes in texture, reliable and quantifiable methods of texture measurement are needed. This study integrated data from a snapping test, confocal laser scanning microscopy (CLSM), and sensory panels to study postharvest textural changes and to predict sensory textural attributes of Firmness, Crispness, Mealiness, and Juiciness. Three separate analyses on fresh, stored, and combined fresh and stored fruit data yielded different predictors for the same sensory attributes. Change in Crispness during storage was successfully predicted by change in Work during storage. Cell number and size were related to fresh fruit texture and its maintenance during storage. Unique textural properties of 'Honeycrisp' were found to be inherited by its progeny.
\end{abstract}

Apple fruit texture and flavor are important traits that guide consumer preference (DaillantSpinnler et al., 1996). The commercial success of any cultivar is dependent on maintenance of these two attributes during storage. The sensory attributes that define apple fruit texture are mainly Firmness (compression Force), Crispness (fracturability, Force required to break apart tissue), Mealiness (graininess, perception of small particles) and Juiciness (amount of moisture released; Meilgaard et al., 1999). This complex set of sensory attributes is derived from a varied set of physical and biochemical properties of the fruit cell wall and is quantitatively inherited (Durel et al., 1998).

Objective measurements of sensory attributes are important for breeding purposes and for generating standardized data for quantitative trait loci analysis and molecular studies (King et al., 2000, 2001). Therefore, instrumental measurements that can reliably predict sensory data are needed (Harker et al., 2002; King et al., 2001).

Apple fruit texture has been estimated by employing compression tests, three point bending

Received for publication 23 Dec. 2004. Accepted for publication $8 \mathrm{Apr}$. 2005. This Work was funded by the Minnesota Agricultural Experiment Station. Mention of a trademark name or proprietary product does not constitute a guarantee by the University of Minnesota. or snapping tests (Bourne, 2002), tensile tests, and puncture tests (Abbott et al., 1984; Harker et al., 2002; Johnston et al., 2001). Nondestructive techniques, including visible-near infrared spectroscopy (NIR), electrical impedance, and magnetic resonance imaging (MRI) have also been used for measuring fruit texture (Harker et al., 1997; Mehinagic et al., 2003). The relevance of such measurements is dependent on how well they predict sensory attributes of texture such as 'Crispness' (Harker et al., 2002). However, there has been no definite conclusion as to which method or combination of methods can best predict texture, especially Crispness. One possible reason for this as speculated by Abbott et al. (1984), is probably the lack of range of sensory and instrumental measurements. This study attempts to predict sensory attributes using genotypes that have a range of values for sensory and instrumental measurements.

Studies have used instrumental measurements to predict sensory texture of fresh fruit (Allan-Wojtas et al., 2003; Karlsen et al., 1999; Mehinagic et al., 2003), both fresh and stored fruit (Abbott et al., 1984) or fruit with some storage treatment (Harker et al., 2002). Sensory attempt has been made to predict changes in sensory texture during storage. In addition to prediction of sensory texture of fresh fruit, an attempt was made in this study to predict changes in sensory attributes during storage attributes change with storage, but so far no from changes in instrumental measurements.

Cell size has been determined to influence fresh fruit texture (Allan-Wojtas et al., 2003). Tissue breakdown during storage was found to be positively correlated to cell size (Letham, 1960). In contrast, Smith (1940) found that varieties with larger cells have better keeping qualities and lower respiratory rates than varieties with smaller cells. Reeve (1953) found an inconsistent relationship between cell size, cell number and keeping quality. The role of cell size and cell number in apple fruit texture and fruit softening needs further investigation.

This study integrates data from a snapping test, confocal laser scanning microscopy and sensory evaluations for 10 apple genotypes. The objective was to determine whether a snapping test and microscopy data could be used to predict variation in sensory attributes among a set of apple genotypes typical of those evaluated in a breeding program and how those attributes change during storage. An attempt was made to predict changes in sensory attributes from snapping test and microscopy data.

\section{Materials and Methods}

Plantmaterials. 'Honeycrisp' apples (used as a standard in texture studies), 'Keepsake', 'Red Prairie Spy', 'McIntosh', 'Zestar! ${ }^{\mathrm{TM}}$ ', 'MN 1706', 'MN 1708', 'MN 1802', 'MN 1868 ', and 'MN 1915' were harvested at their individual commercial harvest maturity date or based on breeder experience in the years 2002 and 2003 from the Horticultural Research Center in Chanhassen, Minn. All genotypes are harvested mid- or late-season in Minnesota. Data suggest that 'Keepsake' is a parent and 'MN1708' a sibling of 'Honeycrisp' (Cabe et al., 2005). 'MN1915' is a progeny of 'Honeycrisp'. The other genotypes are unrelated to 'Honeycrisp' or each other.

Fruit were stored at $0 \pm 0.5^{\circ} \mathrm{C}$ and $95 \%$ to $99 \%$ relative humidity under ambient atmospheric conditions. Sensory and instrumental texture data were collected on fresh fruit and on fruit that had been stored for 4 months for both years and for all genotypes. Snapping test data from fresh fruit were collected within 1 week of harvest. Sensory data were collected after harvest of all ten varieties, which occurred over a 1-month period.

Sensory evaluations. A sensory panel was comprised of 12 members; 7 females and 5 males. All were students or employees of the Department of Horticultural Science, University of Minnesota. Sensory panelists were made aware of the sensory attributes that were tested through discussion of reference standards (Harker et al., 1997).Some of the panelists had previous experience of serving on apple sensory evaluation panels.

Two sessions each for fresh and stored fruit were conducted. Wedges of unpeeled apples, cut parallel to the core, were served to the participants on white plates or in bowls under ambient fluorescent laboratory light. Fruit were taken out of cold storage two hours before serving for both fresh and stored fruit. Each panelist tested one sample from each 
genotype. A panelist tested 10 samples in a period of 35 to $45 \mathrm{~min}$. Samples of all genotypes were randomized using random number tables, coded and served.

An evaluation sheet with four $15 \mathrm{~cm}$ descriptor scales for Crispness, Firmness, Mealiness, and Juiciness was provided to each panelist. Panelists rated the intensity of a particular attribute by drawing a perpendicular line on the scale. A value of 0 on the descriptor scale meant an absence of the attribute and a value of 15 meant an extreme intensity of the attribute. Ratings by the panelists were converted to numerical values from 0 to 15 by manually measuring them with a $15-\mathrm{cm}$ ruler.

Texture analysis. A TA.XT2 texture analyzer (Stable Micro Systems Ltd., Surrey, U.K.) was used to measure fracture Force (Force) using a snapping test as described by Tong et al. (1999). Cylindrical samples $8 \mathrm{~mm}$ thick, supported by two solid supports, were placed $2 \mathrm{~cm}$ apart and fractured with a probe with a convex end $6 \mathrm{~mm}$ in diameter. For each genotype, each year, and each storage treatment (fresh and stored), 10 fruit were analyzed. From the Force-Distance curves, the Force at which the samples fractured and Distance moved by the probe to reach the fracture Force were measured. These values were used to further calculate Work (Force $\times$ Distance), and Slope (Force/Distance).

Confocal laser scanning microscopy (CLSM). A Bio-Rad MRC 1024 laser scanning confocal microscope system (Bio-Rad Laboratories, Hercules, Calif.) was used to study apple fruit tissue for cell size and cell number. CLSM enabled us to view a single layer of cells from the tissue and reduced noise from adjacent layers of cells. Thin, handcut sections, approximately $1 \mathrm{~cm} \times 1 \mathrm{~cm}$, from apple cortex tissue were taken and equilibrated with $0.1 \mathrm{M}$ CAPS buffer, $\mathrm{pH}$ 10.4, (Parker and Waldron, 1995) and viewed by CLSM. Magnification of $20 \times$ was used to obtain images. Images were collected using a computer attached to the Bio-Rad CLS microscope. Ten fruit per genotype were analyzed. Images were saved for further analysis.
Sections of fruit cortex tissue were obtained midway between the peel and core, from an area previously described as inner flesh by Reeve (1953). The face of the cut section was parallel to the longitudinal cross-section of the fruit. Given the spherical shape of apple fruit, this region has the maximum volume, and thus represents most of the edible portion of the fruit.

Image analysis. Cell size and number data were collected for the years, 2002 and 2003. Ten images (one image per fruit) representing ten individual fruit were analyzed for each genotype in each year. Cells were counted manually from images. Cell size was measured using the free hand drawing tool of ImageJ (Ausubel et al., 2003) image analysis software. Each cell boundary was outlined using the drawing tool. Area enclosed by the boundary was calculated using an area calculator plugin (Rasband, 2000).

Statistical analysis. Instrumental and sensory measurements for the 2 years $\times 2$ storage treatments $\times 10$ genotypes were analyzed using SPSS statistical analysis software (11.5 software, SPSS, Inc., Chicago, Ill.). The general linear model univariate and multivariate functions of SPSS were used to understand variation in the data. Means for each variable were compiled separately, and correlation and regression analyses were performed using the SPSS software.

Variation in sensory attributes was studied using genotype, storage time and panelist as the main effects, and the interaction terms genotype $\times$ storage and genotype $\times$ panellist (Table 1$)$. Variation in texture analyzer measurements was studied using genotype and storage as the main effects and the interaction term genotype $\times$ storage (Table 2 ). Genotype and genotype $\times$ year were used to study variation in cell size and cell number data (Table 2). Effect of the year was studied separately for fresh fruit and stored fruit data. Main effects were separated using the Bonferroni mean separation method (Moore and McCabe, 2003).

Linear regressions of sensory attributes on both mechanical and microscopy measure- ments were performed. Separate regression analyses were performed on fresh fruit data, stored fruit data, and combined fresh and stored fruit data to determine whether the same instrumental measurements were the most important predictors at both storage times and for combined data. Objective measurements of Force, Distance, Work, Slope, cell number, and cell size formed the regression equation to predict sensory texture attributes.

Changes in all the measurements between fresh and stored times were calculated and compiled in a separate file. None of the sensory attributes changed significantly for 'Honeycrisp' with storage. Therefore, 'Honeycrisp' was used as a standard and was ascribed a value of one for all sensory attributes. Values given to the other genotypes by the sensory panel were expressed as differences from 'Honeycrisp' values. These differences were calculated separately for fresh and stored fruit. Standardized values thus obtained for stored fruit were subtracted from standardized values for fresh fruit.

Regression analysis of change in sensory attributes during storage on changes in texture analyzer measurement during storage, and microscopy measurements were performed. For this, changes in texture analyzer measurements, cell number and cell size were used as independent variables and changes in sensory attributes during storage were used as dependent variables.

\section{Results}

Variation in sensory and instrumental measures of texture. Both univariate and multivariate analyses of variance (ANOVA) suggested that differences existed among genotypes for all the sensory and instrumental measurements (Tables 1 and 2). Differences also existed between the two storage times and among genotypes at those times for all the sensory and instrumental texture measurements (Tables 1 and 2). Differences due to panelists occurred only for Crispness and Juiciness (Table 1). The interaction genotype $\times$ panelist was not

Table 1. Analysis of variance (ANOVA) table for measurements on sensory attributes. 'Storage' represents data collected on fresh and stored fruit averaged separately for 2 years. Data shown are type IV sum of squares; $\mathrm{df}=$ degrees of freedom

\begin{tabular}{|c|c|c|c|c|c|c|c|c|}
\hline Source & Firmness & $\mathrm{df}$ & Crispness & $\mathrm{df}$ & Mealiness & $\mathrm{df}$ & Juiciness & $\mathrm{df}$ \\
\hline Genotype (G) & $4949^{* * *}$ & 9 & $5646^{* * *}$ & 9 & $2149^{* * *}$ & 9 & $1529^{* * *}$ & 9 \\
\hline Storage (S) & $284^{* * * *}$ & 1 & $292^{* * * *}$ & 1 & $101^{* * * *}$ & 1 & $246^{* * * *}$ & 1 \\
\hline $\mathrm{G} \times \mathrm{S}$ & $364^{* * * *}$ & 9 & $251^{* * * *}$ & 9 & $288^{* * * *}$ & 9 & $256^{\text {**** }}$ & 9 \\
\hline Panelist $(\mathrm{P})$ & $141^{\mathrm{NS}}$ & 11 & $151^{* *}$ & 11 & $123^{\mathrm{NS}}$ & 11 & $281^{* * * *}$ & 11 \\
\hline $\mathrm{G} \times \mathrm{P}$ & $513^{\mathrm{NS}}$ & 96 & $555^{\mathrm{NS}}$ & 96 & $1141^{\mathrm{NS}}$ & 96 & $900^{\mathrm{NS}}$ & 96 \\
\hline Error & 1551 & 253 & 1433 & 249 & 2088 & 246 & 2059 & 255 \\
\hline
\end{tabular}

NS,**,****Nonsignificant or significant at $P<0.001$ or 0.01 , respectively.

Table 2. Analysis of variance (ANOVA) table for instrumental measurements. 'Storage' represents data collected on fresh and stored fruit averaged separately for 2 years. Data shown are type IV sums of squares; $\mathrm{df}=$ degrees of freedom

\begin{tabular}{|c|c|c|c|c|c|c|c|c|c|c|c|c|}
\hline Source & $\begin{array}{l}\text { Force } \\
\left(\times 10^{5}\right)\end{array}$ & df & Distance & df & $\begin{array}{c}\text { Work } \\
\left(\times 10^{5}\right) \\
\end{array}$ & $\mathrm{df}$ & $\begin{array}{l}\text { Slope } \\
\left(\times 10^{5}\right)\end{array}$ & df & $\begin{array}{c}\text { Cell size } \\
\left(\times 10^{5}\right)\end{array}$ & df & $\begin{array}{l}\text { Cell } \\
\text { no. }\end{array}$ & df \\
\hline Genotype (C) & $86^{* * *}$ & 9 & $42^{* * * *}$ & 9 & $1106^{* * * *}$ & 9 & 6 & 9 & $9215^{* * * *}$ & 9 & $367^{* * * *}$ & 9 \\
\hline Storage (S) & $102^{* * *}$ & 1 & $24^{* * * *}$ & 1 & $1194^{* * * *}$ & 1 & 6 & 1 & & & & \\
\hline $\mathrm{G} \times \mathrm{S}$ & $39^{* * *}$ & 9 & $24^{* * * *}$ & 9 & $564^{* * * *}$ & 9 & 2 & 9 & & & & \\
\hline Year (Y) & & & & & & & & & $22^{\mathrm{NS}}$ & & $0.2^{\mathrm{NS}}$ & 1 \\
\hline$G \times Y$ & & & & & & & & & $2889^{\mathrm{NS}}$ & & $117^{\mathrm{NS}}$ & 9 \\
\hline Error & 55 & 369 & 56 & 369 & 1122 & 369 & 4 & 369 & 25217 & 139 & 1118 & 134 \\
\hline
\end{tabular}

NS, ${ }^{* *, * * *}$ Nonsignificant or significant at $P<0.001$ or 0.01 , respectively. 
significant for all the sensory attributes, suggesting that panelists were able to consistently judge genotypic differences in texture.

Among sensory measurements, year was a significant factor for Crispness of fresh and stored fruit and Juiciness of stored fruit (data not shown). Genotype $\times$ year was significant for all sensory attributes except Mealiness of fresh fruit. For stored fruit, genotype $\times$ year was insignificant for all the sensory measurements. Year and genotype $\times$ year were significant for most instrumental texture measurements as determined on fresh and stored fruit data separately (data not shown). Year was not significant for Distance of stored fruit. Genotype $\times$ year was not significant for Distance and Work. Cell number and size did not change with year (Table 2).

Relationship between sensory and instrumentalmeasurements of texture. For fresh fruit data, when sensory attributes were regressed on all the predictors (Force, Distance, Work, Slope, cell number and cell size), the only statistically significant result was the prediction of Crispness with an $r^{2}$ value of 0.67. Stepwise regression analyses on data from fresh fruit showed that Force was the only predictor of sensory Firmness $\left(r^{2}=0.43\right)$. Cell number and Slope were the predictors of Crispness, with $r^{2}=$ 0.57. Cell number and Work were the predictors of Mealiness, with $r^{2}=0.52$. Cell size was the only predictor of Juiciness $\left(r^{2}=0.59\right)$.

For stored fruit data, when all the predictors were included in the regression equation, the $r^{2}$ values for Firmness and Crispness were 0.84 and 0.85 , respectively. This regression analysis yielded statistically insignificant results for Mealiness and Juiciness. Stepwise regression analyses on stored fruit showed that Work was the predictor of Crispness $\left(r^{2}=0.82\right)$. Prediction of Firmness, Mealiness, and Juiciness yielded statistically insignificant results.

For combined data from fresh and stored fruit, when all of the instrumental and microscopy measurements were present in the regression equations for prediction of sensory traits, the coefficients of determination $\left(r^{2}\right)$ were 0.62 for Firmness, 0.66 for Crispness, 0.57 for Mealiness, and 0.41 for Juiciness. Using the stepwise procedure, Work was the only predictor selected for sensory Firmness, with $r^{2}=0.57$. For Crispness, cell number, and Work were the predictors with $r^{2}=0.63$. For Mealiness and Juiciness, Distance was the only predictor selected with $r^{2}$ values of 0.49 and 0.30 , respectively.

Change in texture during storage. Regression with changes in mechanical measurements and microscopic measurements as predictors resulted in prediction of change in Crispness with $r^{2}=0.99$. Using the stepwise regression analysis method, change in Work predicted change in Crispness with $r^{2}=0.76$. Change in Firmness, change in Mealiness, and change in Juiciness were not predicted by any of the changes in objective measurements.

Instrumental and sensory texture. According to the sensory panel, fresh 'Keepsake',
'Honeycrisp', 'MN1802', 'MN 1915', and 'Red Prairie Spy' were significantly firmer than the rest of the genotypes (Fig. 1). Stored 'Honeycrisp', 'Keepsake', 'MN 1802', and 'MN1915' were firmer than the rest of the genotypes. Fresh 'Honeycrisp', 'Keepsake', 'MN1802', and 'MN1915' were significantly crisper than the rest of the genotypes (Fig. 2). Stored 'Honeycrisp' and 'MN1802' were significantly crisper than the rest of the genotypes.

Work values from instrumental tests were generally higher for fresh fruit compared to stored fruit, giving a good estimate of the extent of loss of Crispness and Firmness during storage. 'Keepsake' had the highest Work value when fresh. 'Honeycrisp' and 'MN1802' had the highest Work values for stored fruit. 'Honeycrisp', 'MN1802' and 'MN1915' did not lose Crispness and Firmness during storage as determined from the Work values for fresh and stored fruit (Fig. 3).

Textural properties of 'Honeycrisp' were inherited by its progeny, 'MN 1915'. Both genotypes had similar sensory Firmness, Crispness, and Work values when fresh (Figs. 1, 2, and 3). 'MN 1902', another progeny of 'Honeycrisp', was tested only for 1 year, and it had similar sensory and instrumental texture measurement values as 'Honeycrisp' (data not shown).

Microscopy. There was little variation in cell size or shape within a genotype for the area of cortex examined, which would correspond

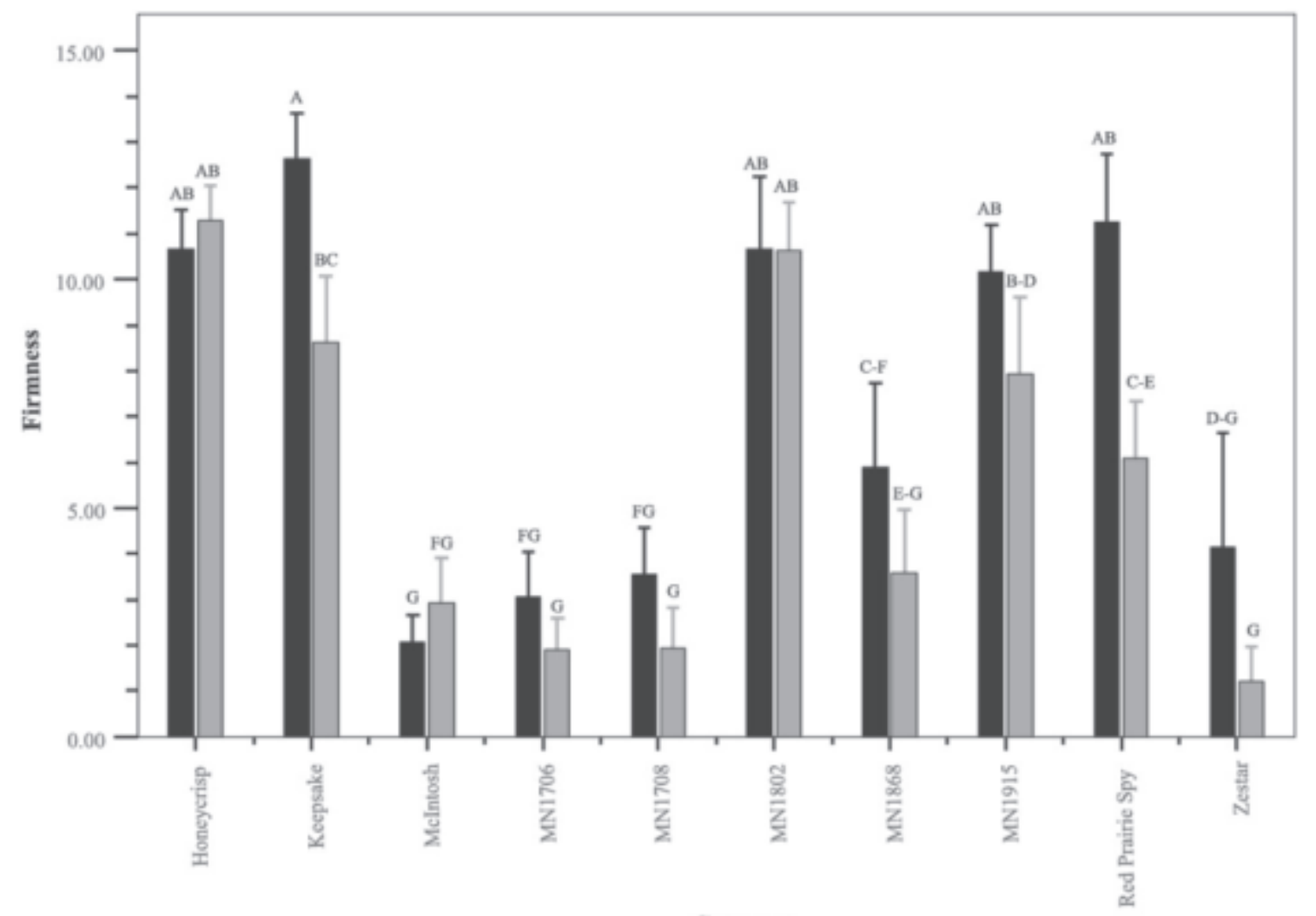

Genotype

Fig. 1. Firmness before and after storage as perceived by the sensory panel. Bars represent mean of Firmness values measured for the years, 2002 and 2003. Letters above bars represent Bonferroni mean separation; the same letters are not significantly different at $P$ $=0.05$. Error bars $=95 \%$ confidence interval $(\mathrm{CI})$ of mean. Black bars $=$ fresh fruit. Grey bars $=$ stored fruit; $\mathrm{n}=24$ (panelist $\times$ year) for each storage time. 


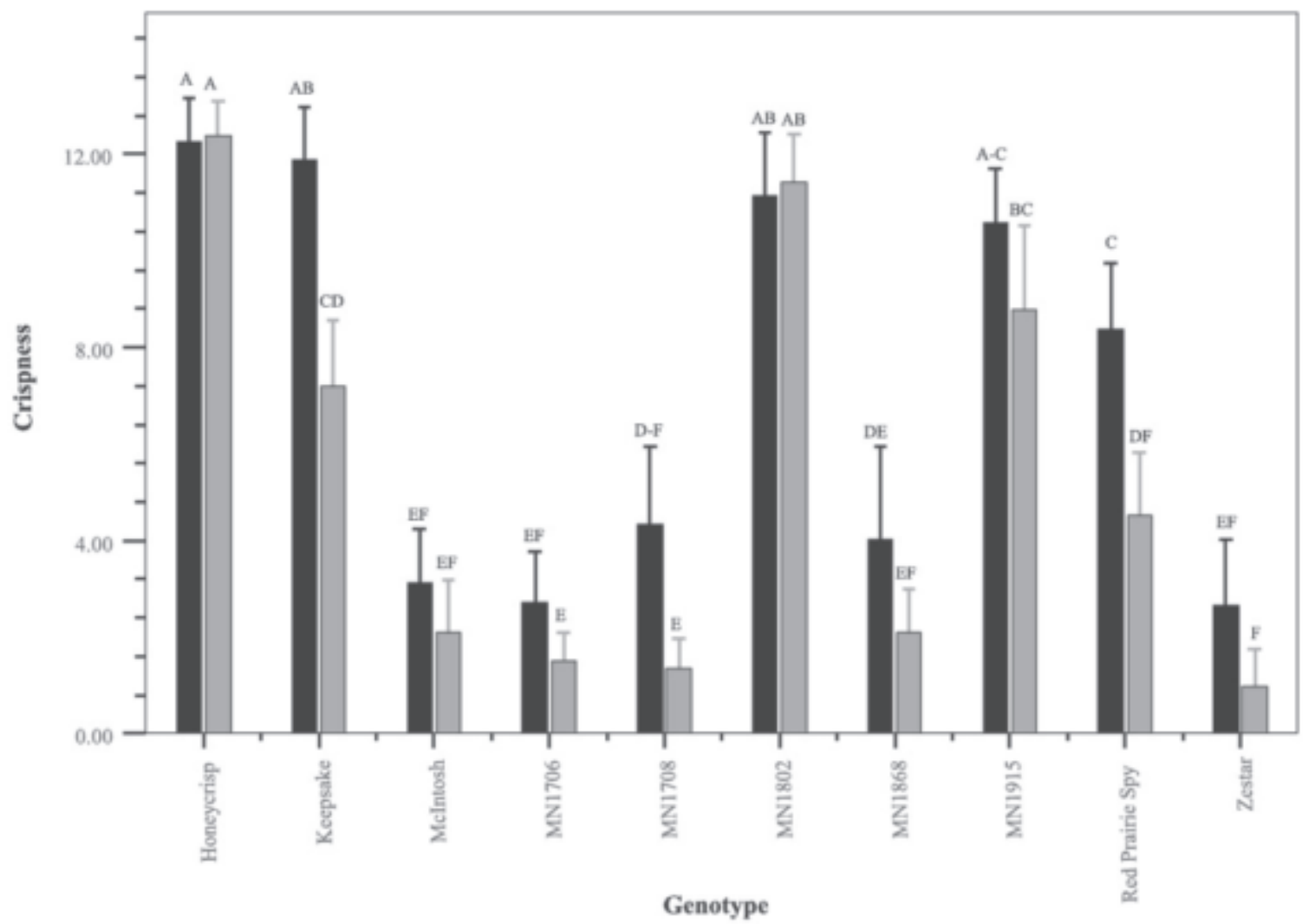

Fig. 2. Crispness before and after storage as perceived by the sensory panel. Bars represent mean Crispness values measured for the years, 2002 and 2003. Letters above bars represent Bonferroni mean separation; the same letters are not significantly different at $P$ $=0.05$. Error bars $=95 \%$ confidence interval $(\mathrm{CI})$ of mean. Black bars $=$ fresh fruit. Grey bars $=$ stored fruit; $\mathrm{n}=24$ (panelist $\times$ year) for each storage time.

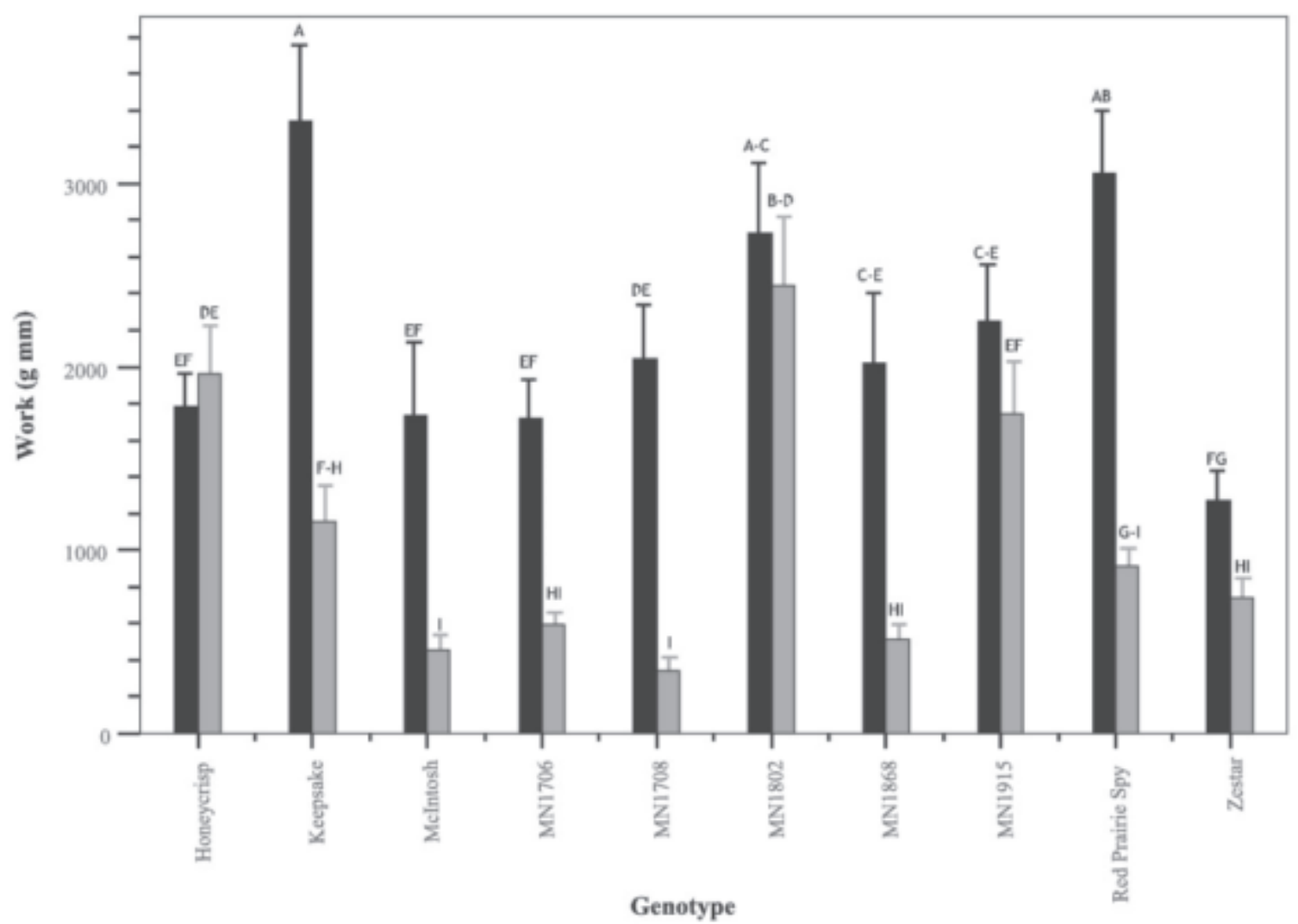

Fig. 3. Work required to fracture fruit tissue samples before and after storage using a TA.XT2 texture analyzer. Bars represent mean of Work values measured for the years, 2002 and 2003. Letters above bars represent Bonferroni mean separation; the same letters are not significantly different at $P=0.05$. Error bars $=95 \%$ confidence interval $(\mathrm{CI})$ of mean. Black bars $=$ fresh fruit. Grey bars $=$ stored fruit; $\mathrm{n}=20$ (genotype $\times$ replication $\times$ year) for each storage time. 


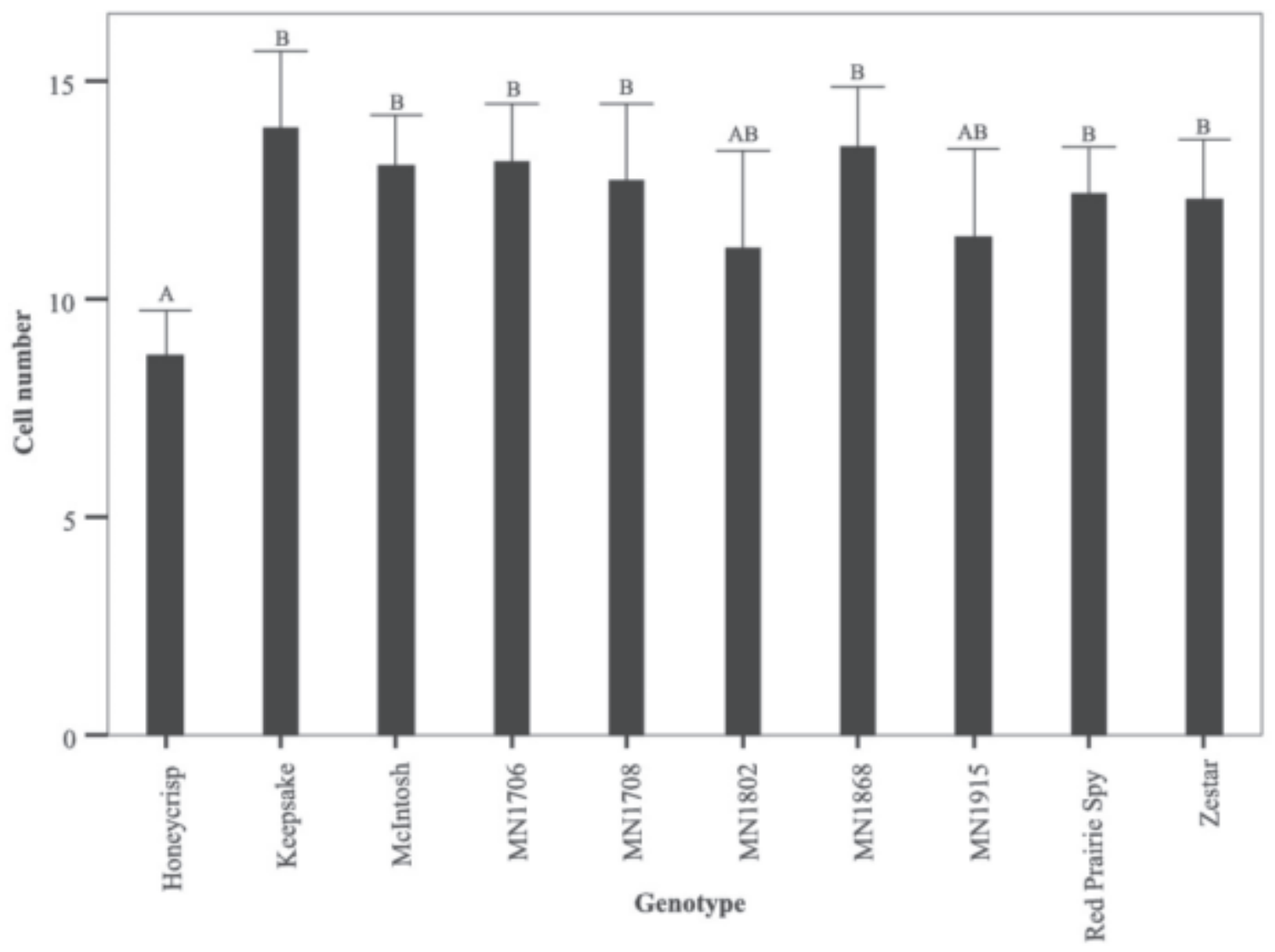

Fig. 4. Cell number per unit area $\left(228580 \mu \mathrm{m}^{2}\right)$ determined using CSLM. Bars represent mean cell number for the years, 2002 and 2003. Letters above bars represent Bonferroni mean separation; the same letters are not significantly different $(P<0.05)$. Error bars $=95 \%$ confidence interval of mean; $\mathrm{n}=10$ (genotype $\times$ replication $\times$ storage $\times$ year $)$.

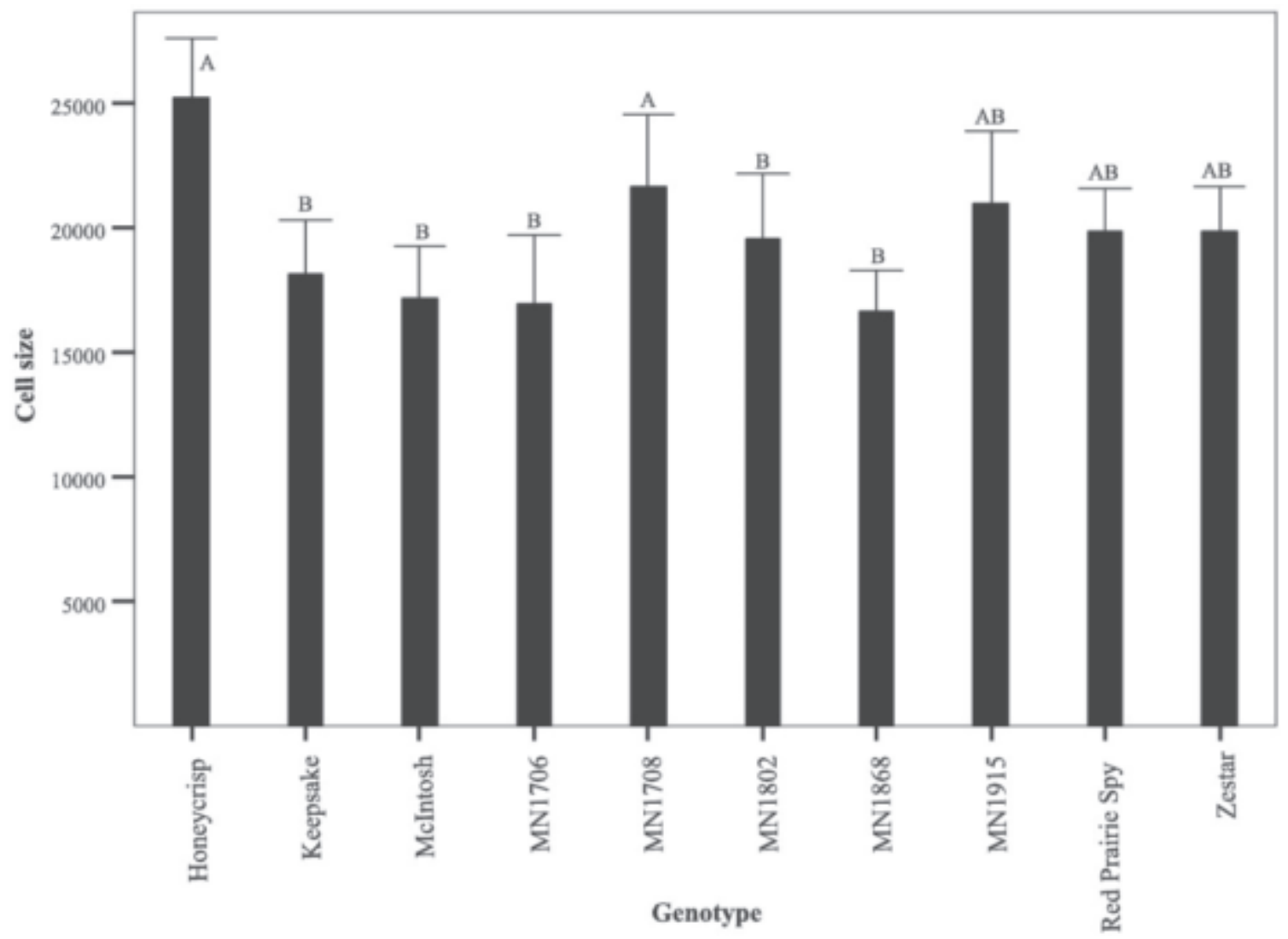

Fig. 5. Average cell size $\left(\mu \mathrm{m}^{2}\right)$ measured using ImageJ software from the CLSM images of apple fruit cortex tissue. Bars represent mean cell size for the years, 2002 and 2003. Letters above bars represent Bonferroni mean separation; the same letters are not significantly different $(P<0.05)$. Error bars $=95 \%$ confidence interval $(C I)$ of mean; $n=10($ genotype $\times$ replication $\times$ storage $\times$ year $)$. 
to half of what Reeve (1953) termed inner flesh. Differences in average cell number and size among genotypes were detected (Figs. 4 and 5). Honeycrisp' had fewer cells per unit area, as did 'MN 1802' and 'MN 1915', compared to the rest of the genotypes (Fig. 4). 'Honeycrisp' and 'MN 1708' had the largest average cell size (Fig. 5). Differences among genotypes in cell number were not always the same for cell size.

\section{Discussion}

Separate analyses on fresh fruit, stored fruit, and combined fresh and stored fruit data showed that the same instrumental measurements were not equally important for all three analyses. Instrumental measurements generally failed to predict sensory evaluations, with the exception of change in Crispness, predicted by change in Work $\left(r^{2}=0.76\right)$, and Crispness of stored fruit, predicted by Work $\left(r^{2}=0.82\right)$. This suggests that although postharvest physiologists interested in Crispness may be able to use instrumental measurements if unable to do sensory evaluations, breeders interested in initial fruit texture will have to continue to rely on sensory panels for fruit evaluation. Turgor pressure is an important factor contributing to apple fruit Firmness (Tong et al., 1999), and its inclusion in this study may have improved the predictability of sensory evaluations by instrumental methods. From the fresh fruit data, cell number was important in predicting variation in the sensory texture attributes of Crispness and Mealiness. This suggests that fruit with fewer cells per unit area are crisper than fruit with a higher number of cells per unit area. Cell size predicted Juiciness, in accordance with a previous finding that apple fruit with larger cells tend to be juicier (AllanWojtas et al., 2003).

The apple genotypes that had fewer numbers of cells in this study ('Honeycrisp', 'MN1802', and 'MN1915') did not lose Crispness during storage as shown by instrumental texture data.
'MN1915', a progeny of 'Honeycrisp', maintained its Crispness as determined by sensory evaluation and instrumental measurements. This suggests that the unique ability of 'Honeycrisp' to maintain its Crispness is heritable and should be explored further.

\section{Literature Cited}

Abbott, J.A., A.E. Watada, and D.R. Massie. 1984 Sensory and instrumental measurement of apple texture. J. Amer. Soc. Hort. Sci. 109:221-228.

Allan-Wojtas, P., K.A. Sanford, K.B. McRae, and S. Carbyn. 2003. An integrated microstructural and sensory approach to describe apple texture. J. Amer. Soc. Hort. Sci. 128:381-190.

Ausubel, F.M., R. Brent, R.E. Kingston, D.D. Moore, J.G. Seidman, J.A. Smith, and K. Struhl. 2003. Current protocols in molecular biology, $\mathrm{p}$. 14.15.1-14.15.9. vol. 3. Wiley, New York.

Bourne, M. 2002. Food texture and viscosity: Concept and measurement. 2nd ed. Academic Press, San Diego, Calif.

Cabe, P.R., A. Baumgarten, K. Onan, J.J. Luby, and D.S. Bedford. 2005. Using microsatellite analysis to verify breeding records: A study of 'Honeycrisp' and other cold-hardy apple cultivars. HortScience, 40:15-17.

Daillant-Spinnler, B., H.J.H. Macfie, P.K. Beyts, and D. Hedderley. 1996. Relationships between perceived sensory properties and major preference directions of 12 genotypes of apples from the southern hemisphere. Food Qual. Prefer. 7:113-126.

Durel, C.E., F. Laurens, A. Fouillet, and Y. Lespinasse. 1998. Utilization of pedigree information to estimate genetic parameters from large unbalanced data sets in apple. Theor. Appl. Genet. 96:1077-1085.

Harker, F.R., J. Maindonald, S.H. Murray, F.A. Gunson, I.C. Hallett, and S.B. Walker. 2002. Sensory interpretation of instrumental measurements 1: Texture of apple fruit. Postharv. Biol. Technol. 24:225-239.

Harker, F. R., R. J. Redgwell, I. C. Hallett, S. H. Murray, and G. Carter. 1997. Texture of fresh fruit. Hort. Rev. 20:121-224.

Johnston, J.W., E.W. Hewett, N.H. Banks, F.R. Harker, and M.L.A.T.M. Hertog. 2001. Physical change in apple texture with fruit temperature:
Effects of genotype and time in storage. Postharv. Biol. Technol. 23:13-21.

Karlsen, A.M., K. Aaby, H. Sivertsen, P. Baardseth, and M.R. Ellekjaer. 1999. Instrumental and sensory analysis of fresh Norwegian and imported apples. Food Qual. Pref. 10:305-314.

King, G.J., C. Maliepaard, J.R. Lynn, F.H. Alston, C.E. Durel, K.M. Evans, B. Griffon, F. Laurens, A.G. Manganaris, E. Schrevens, S. Tartarini, and J. Vergaegh. 2000. Quantitative genetic analysis and comparison of physical and sensory descriptors relating to fruit flesh Firmness in apple (Malus pumila Mill.). Theor. Appl. Genet. 100:1074-1084.

King, G.J., J.R. Lynn, C.J. Dover, K.M. Evans, and G.B. Seymour. 2001. Resolution of quantitative trait loci for mechanical measures accounting for genetic variation in fruit texture of apple (Malus pumila Mill.). Theor. Appl. Genet. 102:1227-1235.

Letham, D.S. 1960. Influence of fertilizer treatment on apple fruit composition and physiology I. Influence on cell size and number. Austral. J. Agr. Res. 12 600-611.

Mehinagic, E., G. Royer, D. Bertrand, R. Symoneaux, F. Laurens, and F. Jourjon. 2003. Relationship between sensory analysis, penetrometry and visible NIR spectroscopy of apples belonging to different genotypes. Food Qual. Pref. $14: 473-484$

Meilgaard, M., G.V. Civille, and B.T. Carr. 1999. Sensory evaluation techniques. 3rd ed. CRC Press, Boca Raton, Fla.

Moore, D.S. and G.P. McCabe. 2003. Introduction to the practice of statistics. 4th ed. Freeman, New York.

Rasband, W. 2000. Area calculator plugin for ImageJ software.http://rsb.info.nih.gov/ij/plugins/area. html.

Reeve, R.M. 1953. Histological investigations of texture in apples. II. Structure and intercellular spaces. Food Res. 18:604-617.

Smith, W.H. 1940. The histological structure of the flesh of the apple in relation to growth and senescence. J. Pomol. Hort. Sci. 18:249-260.

Tong, C., D. Krueger, Z. Vickers, D. Bedford, J. Luby, and A. El Shiekh. 1999. Comparison of softening-related changes during storage of 'Honeycrisp' apple, its parents, and 'Delicious'. J. Amer. Soc. Hort. Sci. 124:407-415. 